\title{
Research Article \\ Effect of Solvent, Dye-Loading Time, and Dye Choice on the Performance of Dye-Sensitized Solar Cells
}

\author{
Fahd M. Rajab \\ Promising Centre of Sensors and Electronic Devices and Department of Chemical Engineering, \\ Najran University, P.O. Box 1988, Najran 11001, Saudi Arabia \\ Correspondence should be addressed to Fahd M. Rajab; fmrajab@nu.edu.sa
}

Received 11 September 2015; Accepted 24 December 2015

Academic Editor: Antonios Kelarakis

Copyright (C) 2016 Fahd M. Rajab. This is an open access article distributed under the Creative Commons Attribution License, which permits unrestricted use, distribution, and reproduction in any medium, provided the original work is properly cited.

Anatase titania films with a thickness of up to $20 \mu \mathrm{m}$ and deposited over a fluorine-doped tin-oxide substrate are impregnated with ruthenium dyes N-719 and N-749 using Dip and supercritical-fluid methods for the purpose of fabricating dye-sensitized solar cell devices. The dyes are dissolved in different solvent mixtures, including supercritical carbon dioxide, as well as combinations of more traditional solvents including mixtures of acetonitrile, and t-butanol. Analytical studies included thin-film analyzing and scanning electron microscopy to measure titania film thickness and porosity, UV-Vis spectroscopy to quantify dye concentration, and current-voltage device characterizations to assess energy conversion efficiency, as well as open-circuit voltage decay measurements and quantum efficiency to examine electron collection efficiency. A significant result is that using the dye N-749 in a solvent that includes supercritical carbon dioxide leads to energy conversion efficiencies that are higher for devices with a thick $20 \mu \mathrm{m}$ semiconductor film than for the case of devices with thinner films, including the $10 \mu \mathrm{m}$ film thickness that is traditionally considered an upper threshold. The supercritical-fluid method for the N-719 dye also enabled shorter impregnation duration than more conventional classical Dip Methods.

\section{Introduction}

The photovoltaic research community has been primarily focusing on optimizing the photovoltaic device structure and material properties to enhance the conversion efficiencies [ 1 , 2]. Dye-sensitized solar cell (DSSC) devices hold significant potential for effective future deployment for the purpose of converting light to electricity at large scales. A main component of a DSSC is a wide bandgap semiconductor film, typically composed of $\mathrm{TiO}_{2}$ or $\mathrm{ZnO}$ nanoparticles and measuring approximately $10 \mu \mathrm{m}$ in thickness. This semiconductor film provides an internal surface area with a sufficiently large high chromophore density aimed at yielding high levels of light absorption in the $400-800 \mathrm{~nm}$ region, where much of the incident solar flux layer is localized. Other relevant components include a monolayer of organic dye molecules absorbed onto the semiconductor film, and a liquid electrolyte containing the iodide/triiodide $\left(\mathrm{I}^{-} / \mathrm{I}_{3}-\right)$ redox couple which interpenetrates the dye-coated nanoparticles [3]. Electrons are promoted into the conduction band of the wide bandgap semiconductor film, due to excitation energy introduced by incident photons, and then diffuse through the film, moving towards a current collector (anode) where they reduce the triiodide that is localized in the electrolyte. The dye is then regenerated by the iodide, thereby closing the cyclic conversion of light to electricity $[4,5]$.

A high electron diffusion coefficient and a low recombination rate constant are key requirements for fabricating highly efficient dye-sensitized solar cells. To date, attempts to improve the efficiency of conversion of solar to electrical energy by thickening the nanocrystalline wide bandgap semiconductor film, seeking to improve its light absorption at red wavelengths, have failed [3,6]. It has been argued that the lack of success is due to the fact that the largest film thickness that can be achieved is limited by the electron diffusion length. Furthermore, higher dye loadings, which are desirable for inducing higher photon harvesting, are also limited by the low diffusion and high recombination rates of the electrons $[3,6]$.

Dye uptake by the semiconductor film becomes essential to improve the light harvesting efficiency of a DSSC material. A monolayer and uniform dye coverage are highly preferred 
to enhance performance. In fact, multilayer formation and poor dye coverage hinder the kinetics of electron transfer. Ono et al. [7] have shown that the agglomeration of dye molecules on $\mathrm{TiO}_{2}$ surfaces causes high charge transfer resistance. Furthermore, dye aggregates cause quenching of photoexcited electrons, interfere with effective electron injections into the semiconductor film, and can favor the highly undesirable recombination of electrons with the electrolyte.

The electron diffusion length is limited by a dynamic competition between electron diffusion and lifetime. Peter [8] argues that the optimum electron diffusion length for typical DSSCs is approximately $10 \mu \mathrm{m}$. To achieve higher device efficiency, it is important to enhance the photoactive surface area by utilizing thicker titania films while still ensuring a higher diffusion length and a low recombination rate. Thicker semiconductor films indeed provide increased surface area. However, poor penetration and dye aggregation effects, which are more pronounced in thicker films, introduce enhanced recombination and electron traps due to transport limitations associated with the liquid solvents used to apply the dye [7]. In summary, increasing the semiconductor film thickness beyond $10 \mu \mathrm{m}$ leads to reduced electron diffusion lengths and increased electron recombination; hence, the $10 \mu \mathrm{m}$ thickness is widely seen as an upper limit beyond which performance is likely to decay. Based on this analysis, semiconductor films with thicknesses greater than $10 \mu \mathrm{m}$ are classified as thick films.

Because supercritical-fluids (SCF) have low surface tension and high diffusivities [9], they are expected to successfully deliver dye to pores of small sizes and into otherwise inaccessible spaces, leading to enhanced dye uptake. Ogomi et al. [10] showed that dye injection using a supercritical solvent can yield a $20 \%$ increase in efficiency, relative to conventional Dip-coating processes. This paper studies the effect of solvent choice on the performance of thick-film DSSCs using different solvent mixtures via Dip and SCF Methods. The wide bandgap semiconductor films considered are made of titania and feature thicknesses of up to $20 \mu \mathrm{m}$, hence exploring device characteristics beyond the conventional $10 \mu \mathrm{m}$ thickness limit. The performance of DSSCs fabricated using the resulting films is characterized using standard analytical techniques, including thin film analyzing and scanning electron microscopy to measure film thickness and to assess the relative porosity of the titania films prepared by different techniques, UV-Vis spectroscopy to quantify dye uptake concentration, current-voltage characterizations to obtain short circuit currents, open-circuit voltage, and fill factors and efficiencies, and quantum efficiency and opencircuit voltage decay measurements to assess incident photon conversion efficiency and electron lifetime.

\section{Materials and Methods}

2.1. Materials. A solution containing $\sim 3 \mathrm{wt} \%$ nanocrystalline titanium dioxide (Ti-nanoxide $\mathrm{T} / \mathrm{SC}$ ) and a paste containing $\sim 18 \mathrm{wt} \%$ nanocrystalline titanium dioxide (Ti-nanoxide T/SP), N-719 and N-749 ruthenium-based dyes, and Iodolyte AN-50 and Platisol were acquired from Solaronix.
The particle size of the titanium dioxide is reported to be $13 \mathrm{~nm}$. Fluorine-doped tin-oxide (FTO) films on glass substrates, serving as counter electrodes, were obtained precut from Thin Film Devices, Inc., and from Solaronix. Acetonitrile and 2-methyl-2-propanol (t-butanol) were purchased from Fisher Scientific. Surolyn was obtained from the DuPont Company and extruded to $40 \mu \mathrm{m}$ thick sheets by the Ran Castle Co. Commercial $25 \mu \mathrm{m}$ and $60 \mu \mathrm{m}$ thick spacers were purchased from Solaronix.

2.2. Titania Film Preparation. Titania films of various thicknesses were pasted onto FTO substrates using two different techniques, namely, (A) for 3-10 $\mu \mathrm{m}$ thick films on FTO glass from Solaronix under atmospheric conditions using 40 and $35 \mu \mathrm{L}$ of Ti-nanoxide T/SC at 570 and $500 \mathrm{RPM}$ for 3 and $5 \mu \mathrm{m}$ thick films, respectively, utilizing a Spin Coater TOP8 , and a screen-printing paste of Ti-nanoxide T/SP for 7 and $10 \mu \mathrm{m}$ by the doctor blade method with scotch tape, and (B) for 7-20 $\mu \mathrm{m}$ thick films on FTO glass from thin films using a screen-printing paste of Ti-nanoxide T/SP under vacuum to control film cracking. The latter technique is described in significant detail in the literature [11]. All films were fabricated with the same area of $0.384 \mathrm{~cm}^{2}$ [4]. After the titania is applied on the FTO glass, the films prepared by technique (A) were sintered on a hot plate at $475^{\circ} \mathrm{C}$ for $30 \mathrm{~min}$ at atmospheric conditions, and those by technique (B) were sintered in a tube furnace (Barnstead type 79300 Thermolyne tube furnace) at $450^{\circ} \mathrm{C}$ for $30 \mathrm{~min}$ at pressures in the range of $5.3 \times 10^{-2}$ to $101.3 \mathrm{kPa}$. The films prepared by technique (B) were then annealed at the same temperature on a hot plate until they became transparent [12]. Finally, the films were cooled to room temperature at a controlled rate of $10^{\circ} \mathrm{C} / \mathrm{min}$. Technique (B) has been shown to prepare defect-free anatase titania films for thicknesses up to $20 \mu \mathrm{m}$ [11].

2.3. Dye Impregnation by Dipping. Solutions with a $3.0 \times$ $10^{-4} \mathrm{M}$ concentration of N-749 or N-719 dyes were, respectively, prepared using the Dip technique with different solvent mixtures. For the N-749 dye, the following two solvent mixtures were used for Dip impregnation: acetonitrile (N-749 Dip 1 Method) and a 1:1 vol\% acetonitrile/t-butanol mixture (N-749 Dip 2 Method). For the N-719 dye, the following two solvent mixtures were used: acetonitrile (N-719 Dip 1 Method) and a 1:1 vol\% acetonitrile/t-butanol mixture (N-719 Dip 2 Method).

Dye multilayer formation can cause reduction of charge injection. The effect of dye-loading time on the performance of DSSCs was investigated to determine adequate dye-loading times and to find relationships between current voltage and quantum efficiency characteristics. The 3, 5, 7, and $10 \mu \mathrm{m}$ films prepared by technique (A) were impregnated using the $\mathrm{N}$ 719 Dip 1 Method at times varying from 3 to 60 hours at a film temperature of $55^{\circ} \mathrm{C}$ while the dye is kept at room temperature. The devices were then constructed using $25 \mu \mathrm{m}$ spacers.

Dyes with varying sensitization capabilities require different driving force for electron injection into titania. The effect of dye on the performance of DSSCs was examined 
to find relationships between current voltage and quantum efficiency characteristics when approaching the upper limit of $10 \mu \mathrm{m}$ film thickness and select dye of better performance for fabricating DSSCs with thick films. The 3, 5, 7, and $10 \mu \mathrm{m}$ films prepared by technique (A) were impregnated using the $N-719$ and $N-749$ Dip 2 Methods at selected times $(9,12,15$, and 18 hours, resp.) at a film temperature of $55^{\circ} \mathrm{C}$ while the dye is kept at room temperature. The devices were then constructed with $60 \mu \mathrm{m}$ spacers.

Dye solvent mixture can hinder transport of dye into small pores due to capillary action, preventing proper dye coverage of the titania. The effect of dye solvent mixture was examined as films are made thicker with the dye of better performance to determine the effect of solvent on the current, voltage, and quantum efficiency characteristics around the nominal upper limit of $10 \mu \mathrm{m}$ film thickness. The 7,10 , and $20 \mu \mathrm{m}$ films prepared by technique (B) were impregnated using the N-749 Dip 1 Method, the N-749 Dip 2 Method, and an N-749 SCF Method (described in the next paragraph) at 1.3 to 48 hours of impregnation at a film temperature of $55^{\circ} \mathrm{C}$ while the dye is kept at room temperature. The devices were then constructed using $40 \mu \mathrm{m}$ spacers.

2.4. Dye Impregnation by the Supercritical Method. The N-749 ruthenium dye was dissolved in a cosolvent to ensure solubility in supercritical carbon dioxide $\left(\mathrm{sc}-\mathrm{CO}_{2}\right)$ [13]. For the N749 dye, the solvent was a $1: 1 \mathrm{vol} \%$ mixture of acetonitrile/tbutanol and sc- $\mathrm{CO}_{2}$. In the suite, we refer to this technique as the N-749 SCF Method, where the acronym SCF is introduced to denote a supercritical-fluid. The optimum concentration of the dye in $\mathrm{sc}-\mathrm{CO}_{2}$ ranged from $0.5 \times 10^{-4}$ to $0.9 \times 10^{-4} \mathrm{M}$ at pressures ranging from 10 to $15 \mathrm{MPa}$ [14]. A volume of $7 \mathrm{~mL}$ of $3.0 \times 10^{-4} \mathrm{M}$ of dye in a solvent was injected in a variablevolume view cell (purchased from Metallic Creations Co.). An Isco syringe pump was used to deliver pressurized carbon dioxide to the view cell using a 6-way valve injection loop at $40^{\circ} \mathrm{C}$ and $100 \mathrm{~atm}$, and the solvent mixture was allowed to reach equilibrium using an egg-shaped stir bar. The cell pressure was increased to $250 \mathrm{~atm}$ by back pressure, for optimal solubility. Titania films placed in the view cell were impregnated for a duration of time between 1.3 and $1.7 \mathrm{hr}$.

2.5. Characterization. A Filmetrics F20 thin-film analyzer and a scanning electron microscope were used to measure the film thickness. Dye concentrations were measured using a nondestructive UV-Vis technique whose details are described elsewhere [15]. Briefly, UV-Vis spectroscopy of the titania films or dye solutions was done in the range of 350 to $650 \mathrm{~nm}$ in a Perkin-Elmer Lambda 9 UV/Vis/NIR spectrometer. The spectra for dyes in the titania films were measured first. The titania films were mounted on an $\mathrm{X}-\mathrm{Z}$ translational stage (Newport), and multiple measurements $(\sim 15)$ of the initial (unimpregnated) and impregnated titania film were obtained. The spectra of the initial and impregnated titania films were averaged for analysis.

2.6. DSSC Device Fabrication and Testing. The FTO counter electrode was painted with Platisol (Solaronix) using a brush

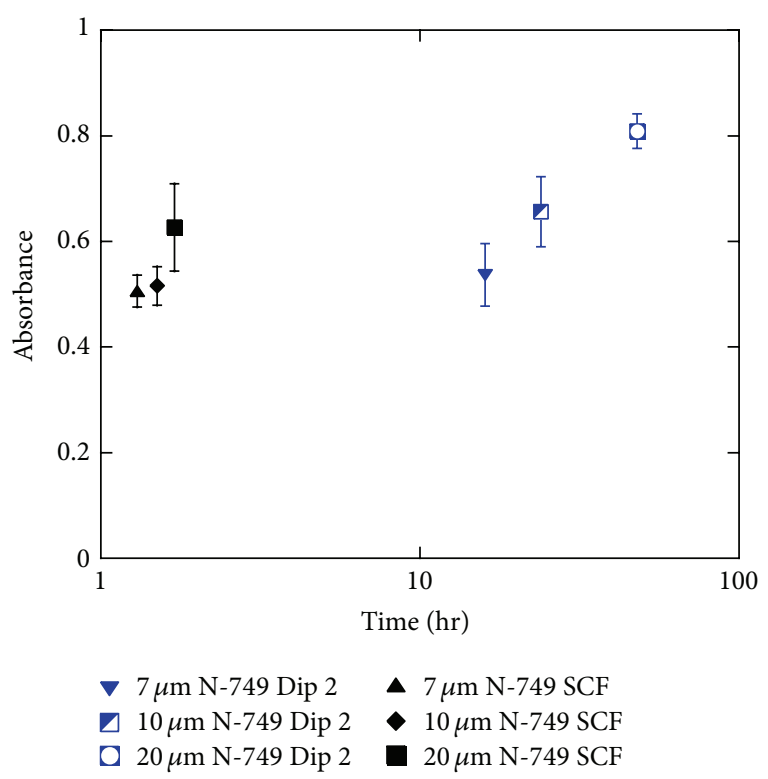

FIGURE 1: Absorbance by UV-Vis spectroscopy of 7, 10, and $20 \mu \mathrm{m}$ thick titania films impregnated with N-749 dye dissolved in solvent mixtures by the N-749 Dip 2 (acetonitrile/t-butanol) and N-749 SCF (acetonitrile/t-butanol/sc- $\mathrm{CO}_{2}$ ) Methods. The horizontal axis shows the total impregnation time for each sample. The N-749 SCF Method achieves absorbances comparable to those of the Dip Method using much shorter impregnation times.

and fired in the tube furnace at $450^{\circ} \mathrm{C}$ for $10 \mathrm{~min}$. A spacer was cut and placed between the electrodes, and the electrolyte was injected by capillary action. The current-voltage characteristics of the prepared DSSCs were measured under simulated AM 1.5 solar light using a source meter (VersaSTAT 3 from Princeton Applied Research) and a solar simulator (Solar Light Co.) along with quantum efficiencies (IV-16 Solar Cell I-V Measurement System from PV Measurements).

The quantum efficiency characteristics of the prepared DSSCs were measured using a QEX7 Solar Cell Spectral Response/Quantum Efficiency/IPCE Measurement System from PV Measurements. Open-circuit voltage decay measurements were used to assess the recombination processes in DSSCs [10]. When all illumination is shut off at open circuit, electron transfers occur by recombination only, and voltage decay can then be related to electron lifetime. The voltage changes were fit to a decay function, and the derivative of the function was used to calculate the electron lifetime using the equation $\tau_{n}=\left(k_{B} T / e\right)(\partial V / \partial t)^{-1}$, where $k_{B}$ is Boltzmann's constant, $T$ is the temperature, $e$ is the electron charge, $V$ is the voltage, and $t$ is time. The ratio $k_{B} T / e$ is the thermal voltage, which at room temperature has the value of $0.026 \mathrm{~V}$.

\section{Results and Discussion}

3.1. Dip versus SCF Impregnation. Titania films with thicknesses of $3,5,7$, and $10 \mu \mathrm{m}$ on FTO substrates were impregnated by the Dip Methods 1 and 2, while titania films of thickness of 7, 10, and $20 \mu \mathrm{m}$ by the Dip Methods 1 and 2 and by the SCF Method use both N-719 and N-749 dyes. The films were analyzed for dye concentration using 


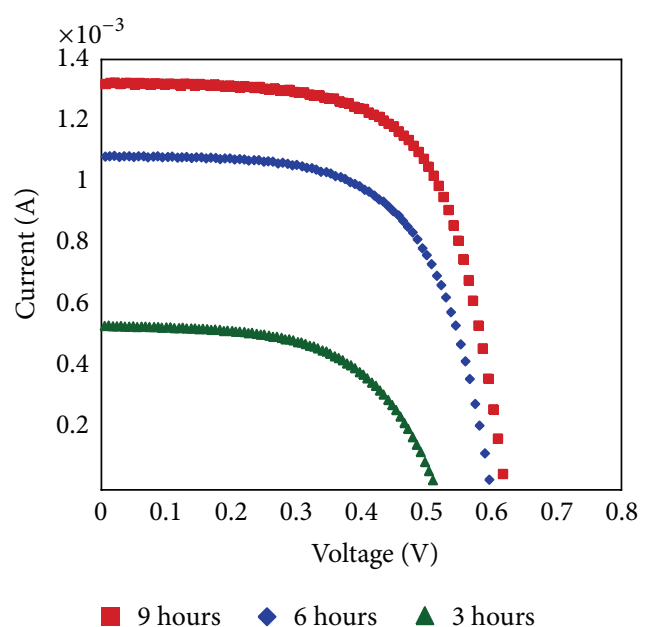

(a)

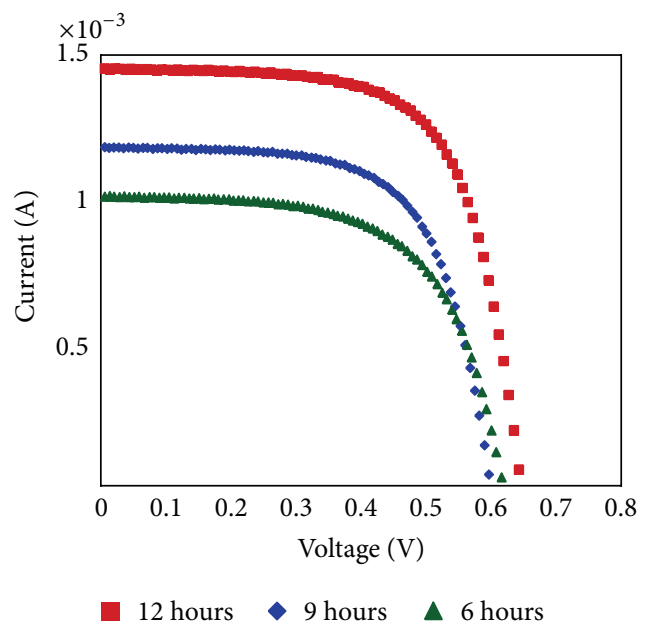

(c)

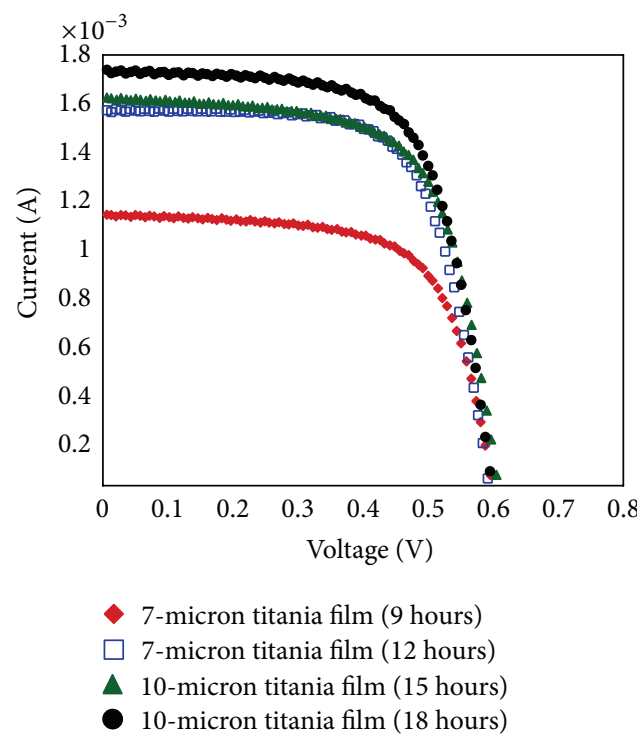

(e)

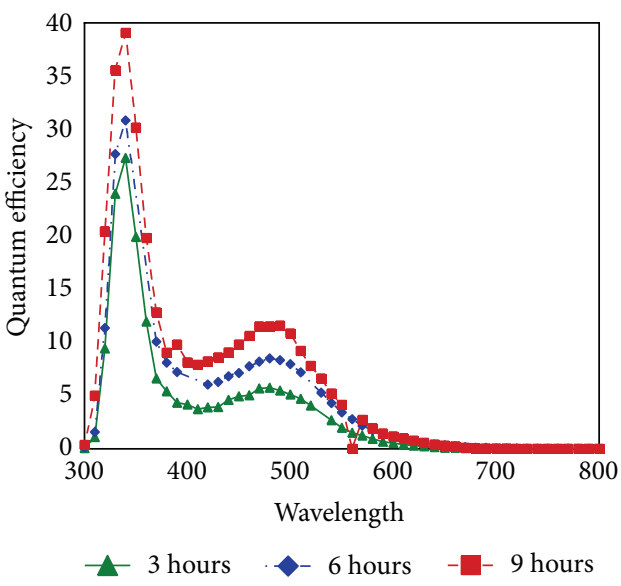

(b)

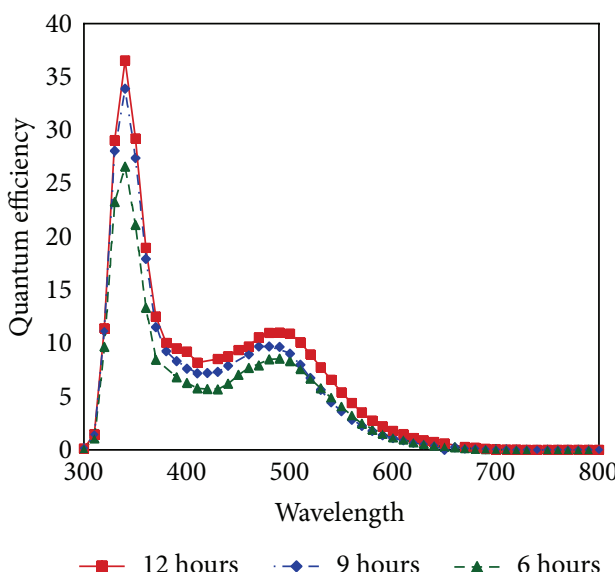

(d)

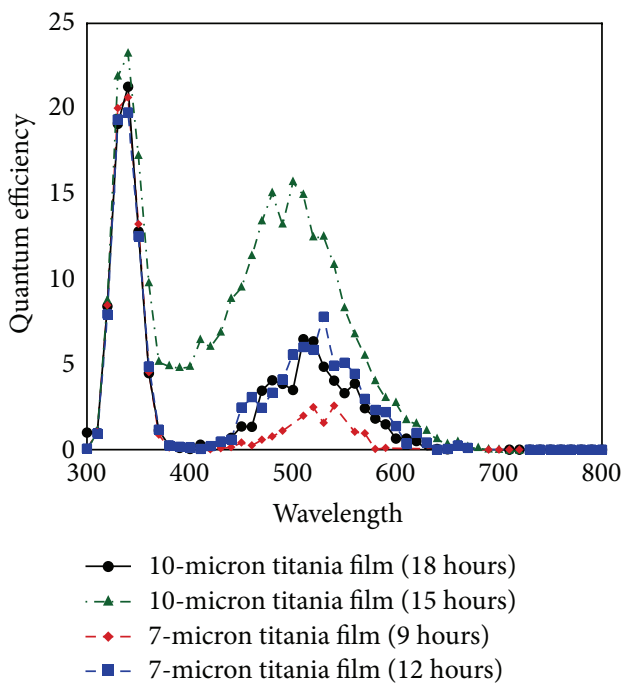

(f)

FIGURE 2: Current-voltage curves for DSSC devices prepared with (a) 3, (c) 5, (e) 7, and $10 \mu \mathrm{m}$ thick titania films impregnated with N-719 dye at impregnation times from 3 to 18 hours. Quantum efficiency curves for DSSC devices prepared with (b) 3, (d) 5, (f) 7, and $10 \mu \mathrm{m}$ thick titania films impregnated with N-719 dye at impregnation times from 3 to 18 hours. The vertical axes on (a), (c), and (e) show increased current for increased impregnation time for all devices. The vertical axes on (b), (d), and (f) show less improvement of quantum efficiency as films are made thicker. The quantum efficiency peaks at 15 hours for $10 \mu \mathrm{m}$ thick films (f). 


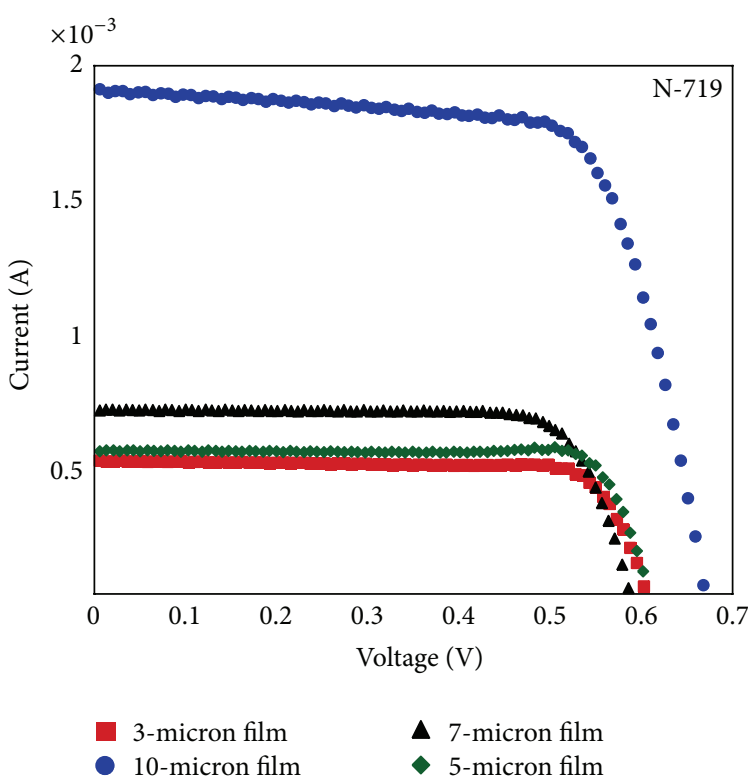

(a)

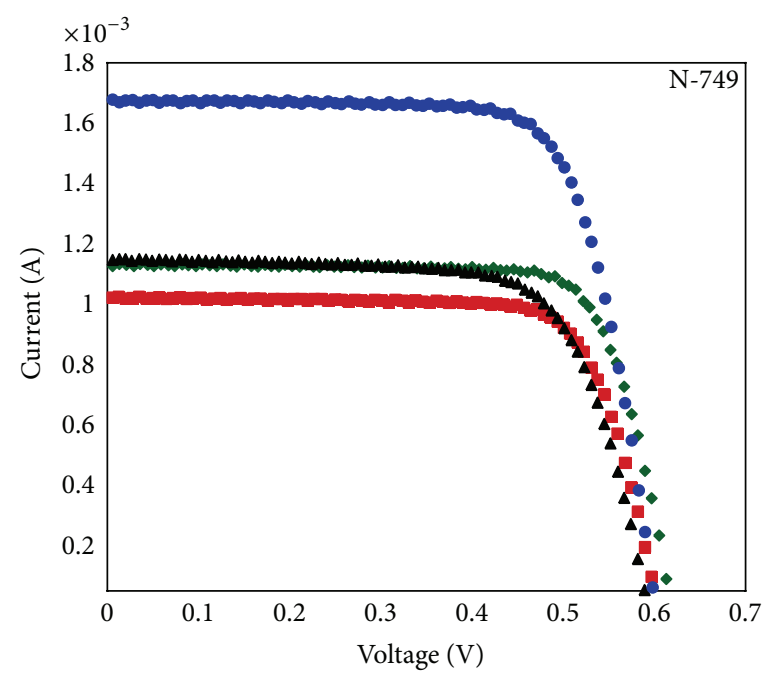

3-micron film -5-micron film

(c)
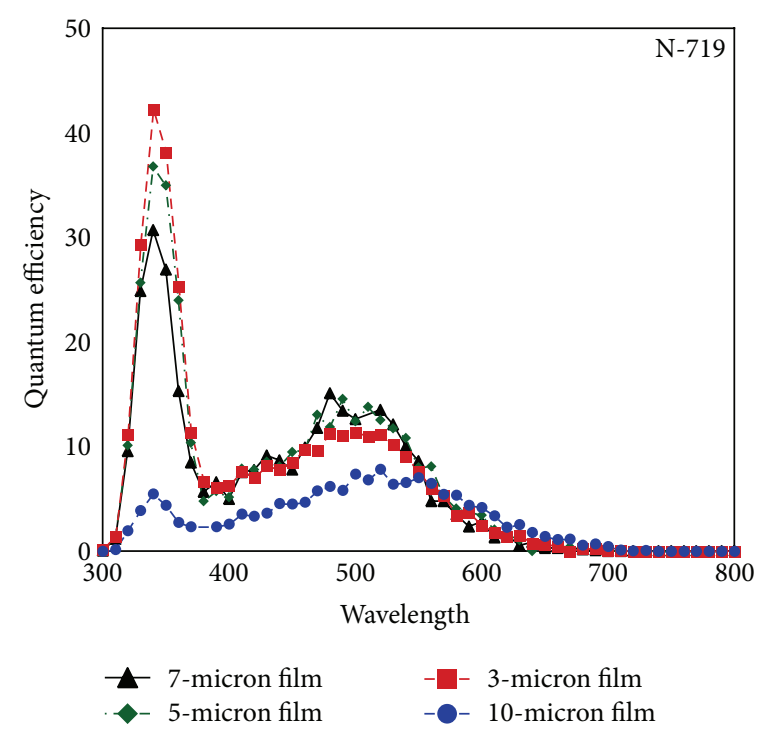

(b)

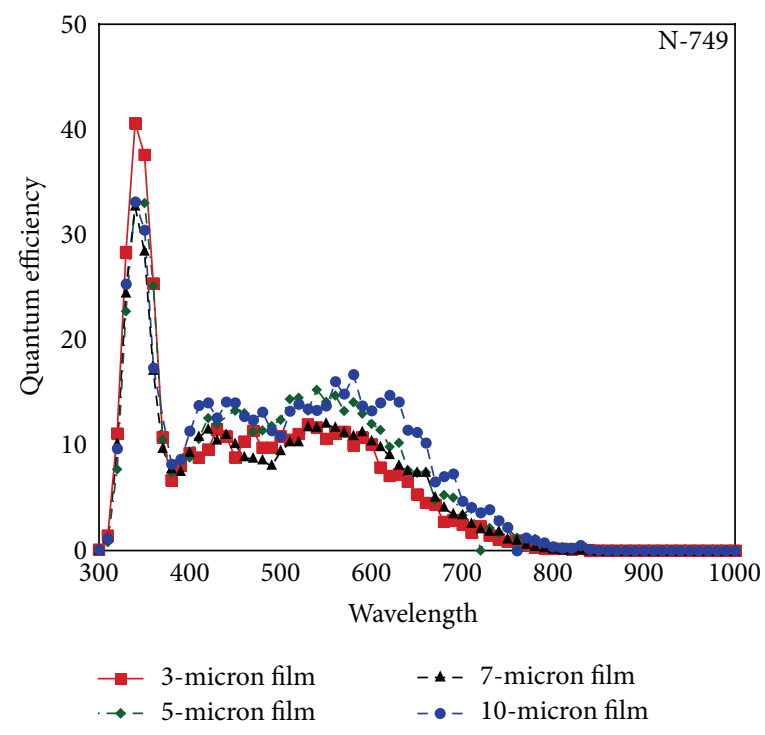

(d)

FIGURE 3: Current-voltage curves for DSSC devices prepared with 3, 5, 7, and $10 \mu \mathrm{m}$ thick titania films impregnated with (a) N-719 and (c) N-749 dyes at optimum impregnation times. Quantum efficiency curves for DSSC devices prepared with 3, 5, 7, and $10 \mu \mathrm{m}$ thick titania films impregnated with (b) N-719 dye and (d) N-749 at optimum impregnation times. The vertical axes on (a) and (c) show increased current for increased thickness for both dyes. The vertical axes on (b) show drop in quantum efficiency as films are made thicker for N-719 dye but they show increase in quantum efficiency for $\mathrm{N}-749$ dye $(\mathrm{d})$.

a nondestructive technique [15]. The SCF Method delivered comparable absorbance to the Dip Methods 1 and 2; however, the supercritical-fluid technique required a much shorter application time. As an illustration of this claim, Figure 1 shows the maximum absorbance obtained as a function of impregnation time for films treated by the N-749 Dip 2 Method (acetonitrile/t-butanol) and by the N-749 SCF Method (acetonitrile/t-butanol/sc- $\mathrm{CO}_{2}$ ).

The figure shows that comparable absorbance with sc$\mathrm{CO}_{2}$ as a solvent ingredient can be achieved in 1.3-1.7 hr, which is a much shorter period of time than the up to $48 \mathrm{hr}$ duration required under the acetonitrile/t-butanol solvent mixture of the N-749 Dip 2 Method.

3.2. The Effect of Dye-Loading Time. Current-voltage characteristics were obtained for N-719 DSSC devices with films prepared to determine the effect of the dye-loading time on charge injection. Figures 2(a), 2(c), and 2(e) show that, for all film thicknesses considered, the energy conversion efficiency inferred from the current-voltage curves presented in these 
graphs increases as the dye-loading times increase. However, as expected, Figures 2(b), 2(d), and 2(f) show that the available room of improvement for quantum efficiency decreases as the films become thicker. For the $10 \mu \mathrm{m}$ films, while the energy conversion efficiency is higher at the maximum dyeloading time of 18 hours, the quantum efficiency peaks at 15 hours and then drops at 18 hours, as seen in Figure 2(f). This indicates that recombination effects start to reverse the increasing trend as a result of multilayer formation, which causes quenching of the photoexcited electrons and leads to a reduction of charge injection [15].

3.3. The Effect of Dye. Current-voltage characteristics were obtained for N-719 and N-749 DSSC devices with films prepared to determine the effect of dye on electron injection. Figures 3(a) and 3(c) show that the energy conversion efficiency derived from the current-voltage curves presented in the graphs increases as the thickness of the film is increased for both dyes. However, Figures 3(b) and 3(d) show that only dye $\mathrm{N}-749$ realizes a consistent increase in quantum efficiency as the thickness is increased up to $10 \mu \mathrm{m}$. This leads us to hypothesize that we can use N-749 for making DSSCs with films thicker than $10 \mu \mathrm{m}$ films, utilizing the larger bandgap sensitization capability of N-749 at a wavelength of $920 \mathrm{~nm}$ compared with that of N-719 of $700 \mathrm{~nm}$, and reduced driving force for electron injection.

3.4. The Effect of Dye Solvent Mixture. The current-voltage characteristics were obtained for N-749 DSSCs made with thicker films ranging from 7 to $20 \mu \mathrm{m}$ prepared by technique (B) at $5.3 \times 10^{-2} \mathrm{kPa}$ and impregnated in N-749, using the $N$ 749 Dip 1 Method (based on acetonitrile), the N-749 Dip 2 Method (based on the acetonitrile/t-butanol solvent mixture), and the SCF Method (based on the acetonitrile/t-butanol/sc$\mathrm{CO}_{2}$ solvent mixture). Figure 4 shows the energy conversion efficiency derived from the current-voltage curves for devices fabricated using these three dye impregnation methods.

An analysis of the figure shows that for each method the efficiency first increases as the semiconductor film thickness increases from 7 to $10 \mu \mathrm{m}$. For the case of the N-749 Dip 1 and N-749 Dip 2 Methods, the efficiency then drops when the film thickness is further increased to $20 \mu \mathrm{m}$. In contrast, the efficiency of the devices with a $20 \mu \mathrm{m}$ semiconductor film actually increases beyond that of the thinner films when the impregnation is carried out using the N-749 SCF Method. The drop in efficiency of the $20 \mu \mathrm{m}$ film case under the N-749 Dip 1 and 2 Methods can be attributed to a poor penetration of solvents into the small pores as shown in Figure 5, consequently reducing the coverage and the electron collection efficiency.

This hypothesis is supported by the fact that the thicker $(20 \mu \mathrm{m})$ films treated by the N-749 SCF Method show an increase in efficiency to $6.57 \%$, a fact that can be attributed to the higher diffusivity and lower surface tension of the solvent phase. The improved performance realized by DSSCs fabricated with a $20 \mu \mathrm{m}$ thick film and impregnated with $\mathrm{N}$ 749 dye using the N-749 SCF Method is most likely due to the

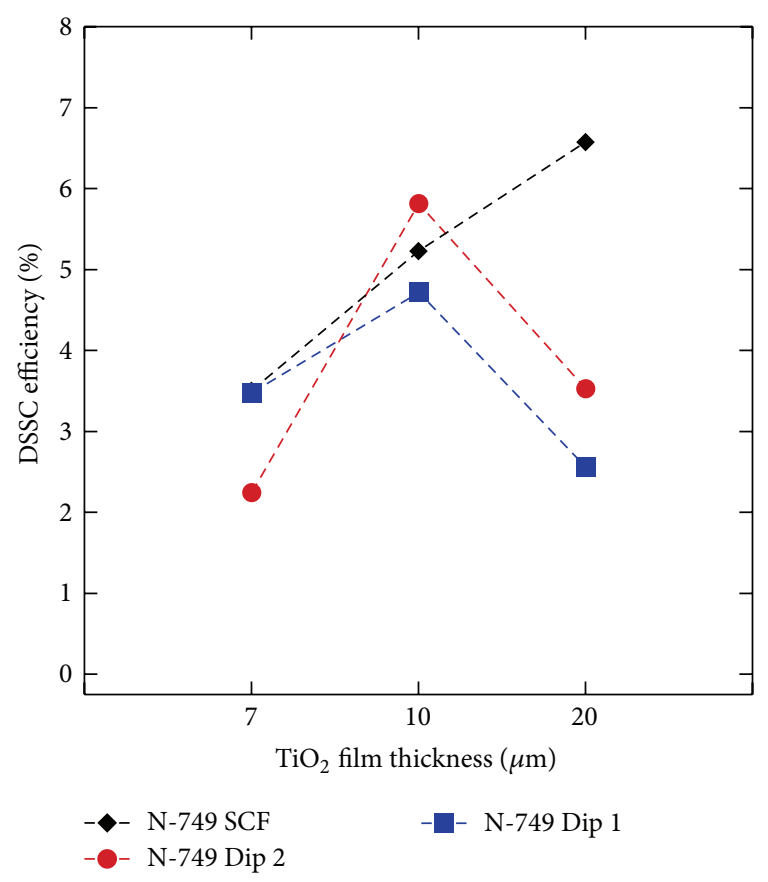

FIGURE 4: Efficiency of DSSC devices prepared with 7, 10, and $20 \mu \mathrm{m}$ thick titania films impregnated with N-749 dye dissolved in a solvent mixture by the N-749 Dip 1 (acetonitrile), N-749 Dip 2 (acetonitrile/t-butanol), and N-749 SCF (acetonitrile/t-butanol/sc$\mathrm{CO}_{2}$ ) Methods. The N-749 SCF Method achieves the highest efficiency for the device prepared with the thickest $(20 \mu \mathrm{m})$ film, whereas the efficiency of the thick-film devices impregnated by the N-749 Dip 1 and N-749 Dip 2 Methods is significantly lower.

improved film coverage that is obtained by the presence of sc- $\mathrm{CO}_{2}$ in the solvent.

The electron lifetime for DSSCs prepared with different titania thicknesses under the N-749 Dip 1, the N-749 Dip 2, and the N-749 SFC Methods of impregnation for the N-749 dye is shown in Figure 6.

The figure indicates that, in all cases, the devices fabricated using the N-749 SCF Method have comparable electron lifetimes to those fabricated using the N-749 Dip 1 and N-749 Dip 2 Methods, provided that the measurement error bars are taken into consideration. This observation implies that the $N$ 749 SCF Method also achieves comparable dye coverage.

\section{Conclusions}

It was shown that charge collection decreases as dye-loading time increases when films are made thicker. It was also shown that quantum efficiency continues to rise at the nominal thickness of $10 \mu \mathrm{m}$ when a dye of higher sensitization capability such as N-749 dye is used. In order to properly utilize DSSCs with thick films, a solvent mixture of low surface tension is critical to enhance solubility and diffusivity of the acetonitrile solvent mixture using t-butanol and sc- $\mathrm{CO}_{2}$. Although adding t-butanol helped enhance the efficiency of the devices fabricated with $10 \mu \mathrm{m}$ films, it was only the mixture of the N-749 SCF Method that allowed achieving higher efficiency for the $20 \mu \mathrm{m}$ thick films. These results 


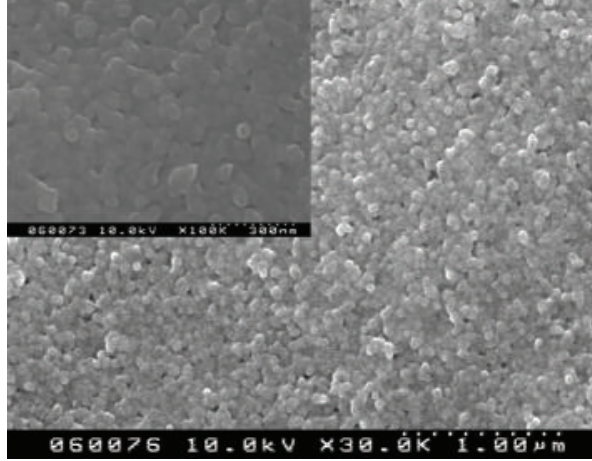

(a)

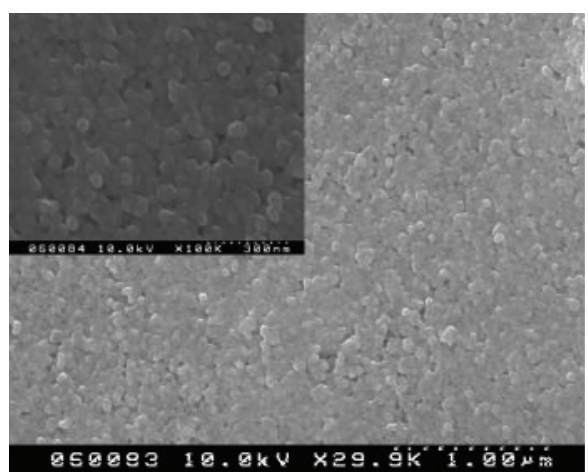

(b)

FIGURE 5: SEM images of thick titania films, prepared by technique (B), show porosity reduction of titania films sintered at lower pressure of $5.3 \times 10^{-2} \mathrm{kPa}$ (b) compared with those sintered at atmospheric pressure of $101.3 \mathrm{kPa}$ (a).

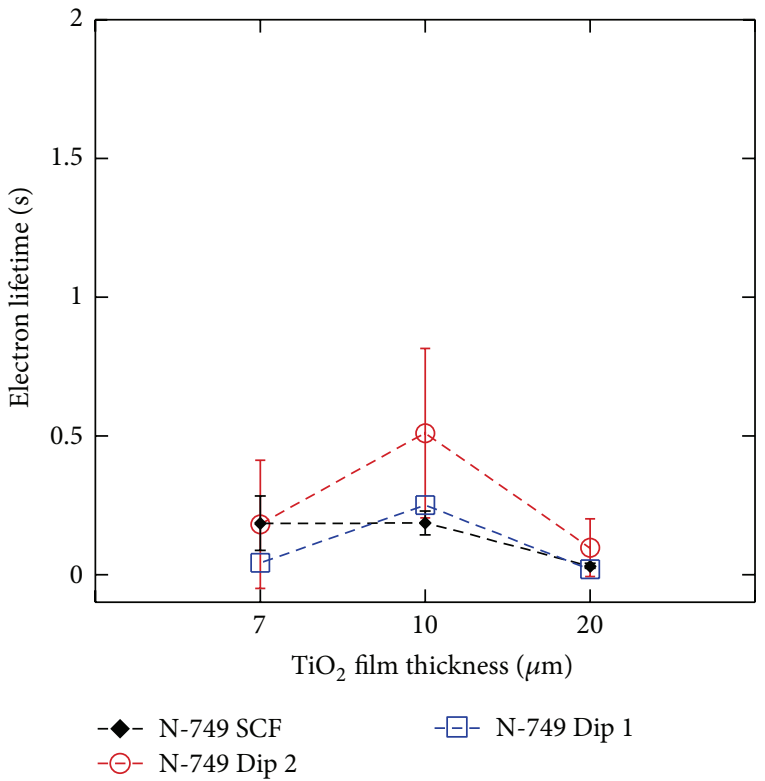

FIGURE 6: Electron lifetime of DSSC devices prepared with 7,10, and $20 \mu \mathrm{m}$ thick titania films impregnated with $\mathrm{N}-749$ dye dissolved in a solvent mixture by the N-749 Dip 1 (acetonitrile), N-749 Dip 2 (acetonitrile/t-butanol), and N-749 SCF (acetonitrile/t-butanol/sc$\mathrm{CO}_{2}$ ) Methods. The SFC Method shows electron lifetimes that are comparable to those achieved by the Dip Methods.

illustrate convincingly the importance of solvent mixture selection for enhancing dye coverage for thick-film DSSCs.

\section{Conflict of Interests}

The author declares that there is no conflict of interests regarding the publication of this paper.

\section{Acknowledgments}

The author acknowledges the support of the Ministry of Higher Education, Kingdom of Saudi Arabia, for this research through NU54/12 and PCSED-004-11 funded project under the Promising Center for Sensors and Electronic Devices at Najran University, Kingdom of Saudi Arabia.

\section{References}

[1] N. Yantara, D. Sabba, F. Yanan et al., "Loading of mesoporous titania films by $\mathrm{CH}_{3} \mathrm{NH}_{3} \mathrm{PbI}_{3}$ perovskite, single step vs. sequential deposition," Chemical Communications, vol. 51, pp. 4603-4606, 2015.

[2] D. Shi, V. Adinolfi, R. Comin et al., "Low trap-state density and long carrier diffusion in organolead trihalide perovskite single crystals," Science, vol. 347, no. 6221, pp. 519-522, 2015.

[3] M. Law, L. E. Greene, J. C. Johnson, R. Saykally, and P. Yang, "Nanowire dye-sensitized solar cells," Nature Materials, vol. 4, no. 6, pp. 455-459, 2005.

[4] A. C. Fisher, L. M. Peter, E. A. Ponomarev, A. B. Walker, and K. G. U. Wijayantha, "Intensity dependence of the back reaction and transport of electrons in dye-sensitized nanocrystalline $\mathrm{TiO}_{2}$ solar cells," The Journal of Physical Chemistry B, vol. 104, no. 5, pp. 949-958, 2000.

[5] M. Grätzel, "Solar energy conversion by dye-sensitized photovoltaic cells," Inorganic Chemistry, vol. 44, no. 20, pp. 6841-6851, 2005.

[6] M. Law, L. E. Greene, A. Radenovic, T. Kuykendall, J. Liphardt, and $\mathrm{P}$. Yang, " $\mathrm{ZnO}-\mathrm{Al}_{2} \mathrm{O}_{3}$ and $\mathrm{ZnO}-\mathrm{TiO}_{2}$ core-shell nanowire dye-sensitized solar cells," Journal of Physical Chemistry B, vol. 110, no. 45, pp. 22652-22663, 2006.

[7] T. Ono, T. Yamaguchi, and H. Arakawa, "Influence of dye adsorption solvent on the performance of a mesoporous $\mathrm{TiO}_{2}$ dye-sensitized solar cell using infrared organic dye," Journal of Solar Energy Engineering, vol. 132, no. 2, Article ID 021101, 2010.

[8] L. Peter, "Transport, trapping and interfacial transfer of electrons in dye-sensitized nanocrystalline solar cells," Journal of Electroanalytical Chemistry, vol. 599, no. 2, pp. 233-240, 2007.

[9] A. A. Clifford and J. R. Williams, Supercritical Fluid Methods and Protocols, Humana Press, Totowa, NJ, USA, 2001.

[10] Y. Ogomi, S. Sakaguchi, T. Kado, M. Kono, Y. Yamaguchi, and $\mathrm{S}$. Hayase, "Ru dye uptake under pressurized $\mathrm{CO}_{2}$ improvement of photovoltaic performances for dye-sensitized solar cells," Journal of the Electrochemical Society, vol. 153, no. 12, Article ID 062612JES, pp. A2294-A2297, 2006. 
[11] F. M. Rajab, D. Loaring, and K. J. Ziegler, "Preparing thick, defect-free films of anatase titania for dye-sensitized solar cells," Thin Solid Films, vol. 519, no. 19, pp. 6598-6604, 2011.

[12] T. Oekermann, D. Zhang, T. Yoshida, and H. Minoura, "Electron transport and back reaction in nanocrystalline $\mathrm{TiO}_{2}$ films prepared by hydrothermal crystallization," Journal of Physical Chemistry B, vol. 108, no. 7, pp. 2227-2235, 2004.

[13] T. T. Ngo, D. Bush, C. A. Eckert, and C. L. Liotta, "Spectroscopic measurement of solid solubility in supercritical fluids," AIChE Journal, vol. 47, no. 11, pp. 2566-2572, 2001.

[14] Y. Ogomi, Y. Kashiwa, Y. Noma et al., "Photovoltaic performance of dye-sensitized solar cells stained with black dye under pressurized condition and mechanism for high efficiency," Solar Energy Materials and Solar Cells, vol. 93, no. 6-7, pp. 1009-1012, 2009.

[15] F. M. Rajab, "Novel nondestructive measurement of dye adsorption on solid titania films for dye sensitized solar cells," Journal of Minerals and Materials Characterization and Engineering, vol. 2, no. 3, pp. 169-175, 2014. 

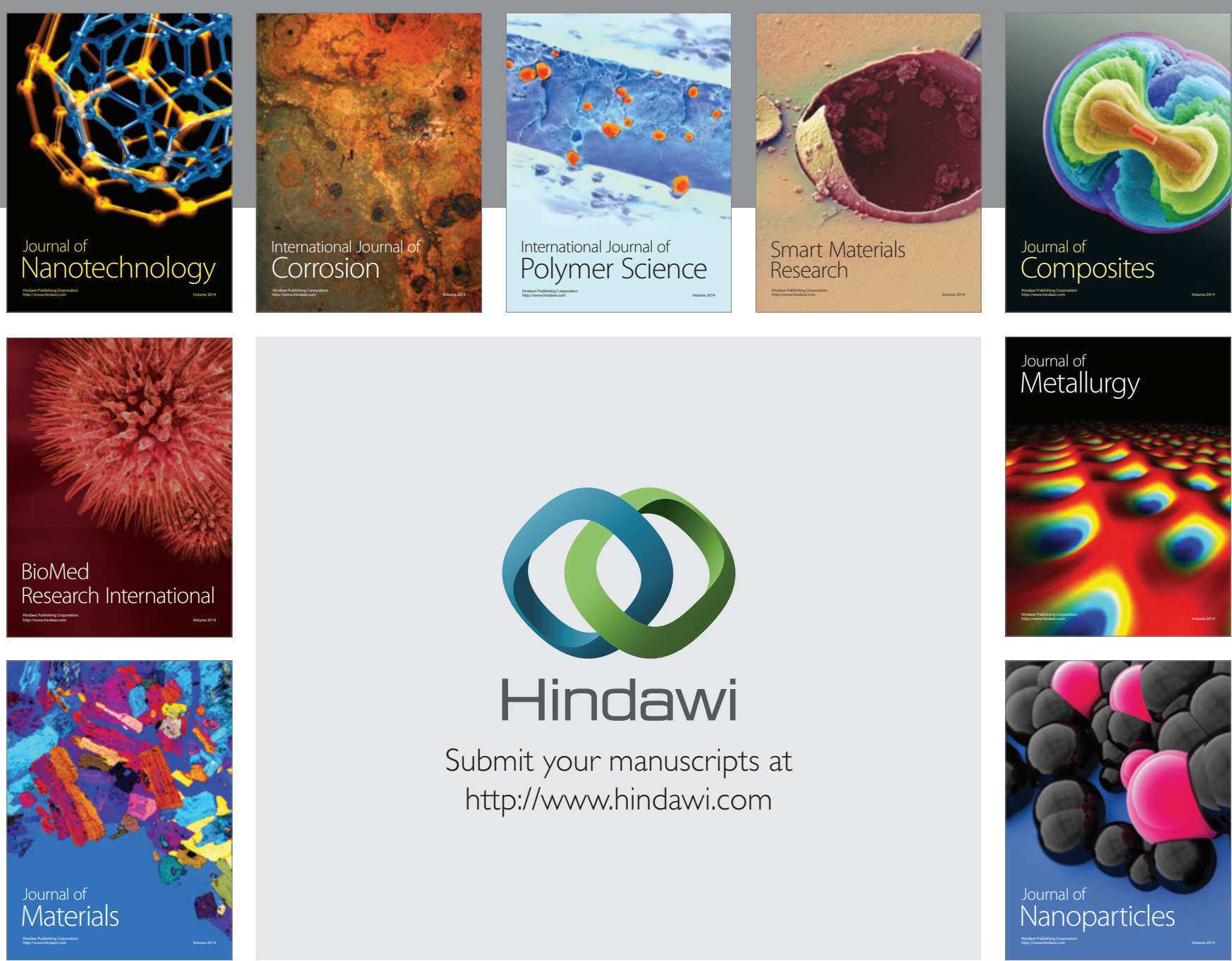

\section{Hindawi}

Submit your manuscripts at

http://www.hindawi.com

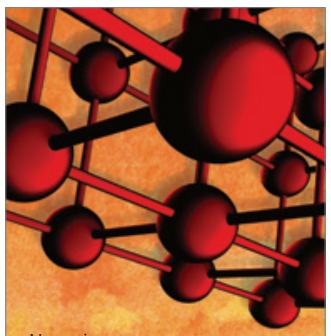

Materials Science and Engineering
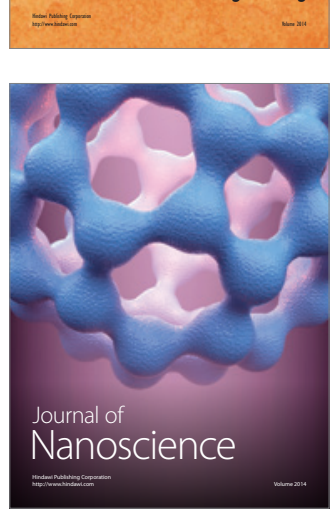
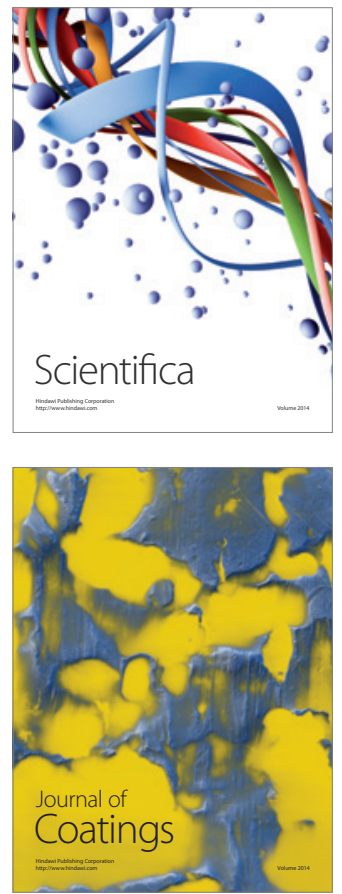
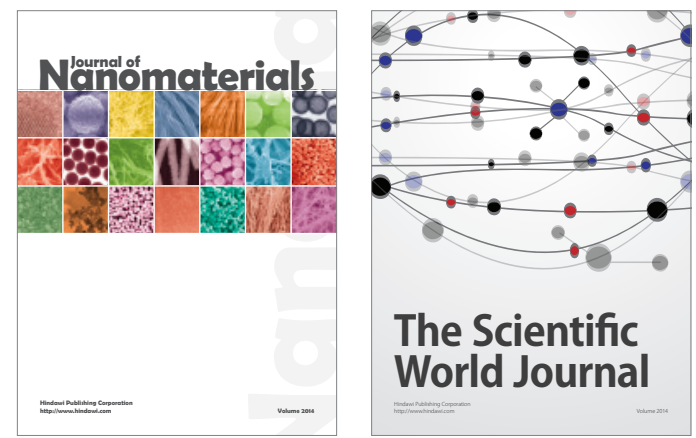

The Scientific World Journal
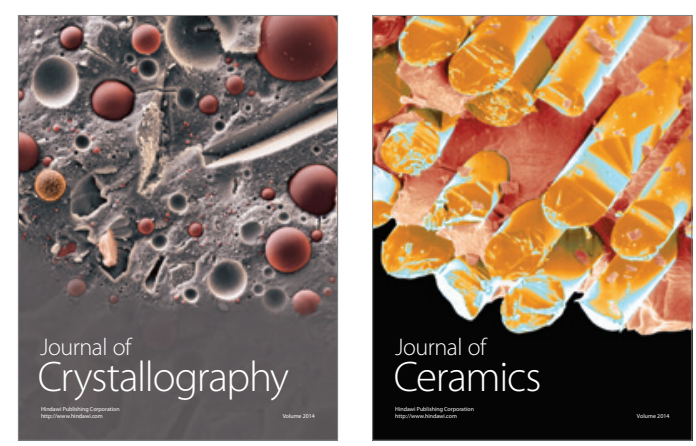
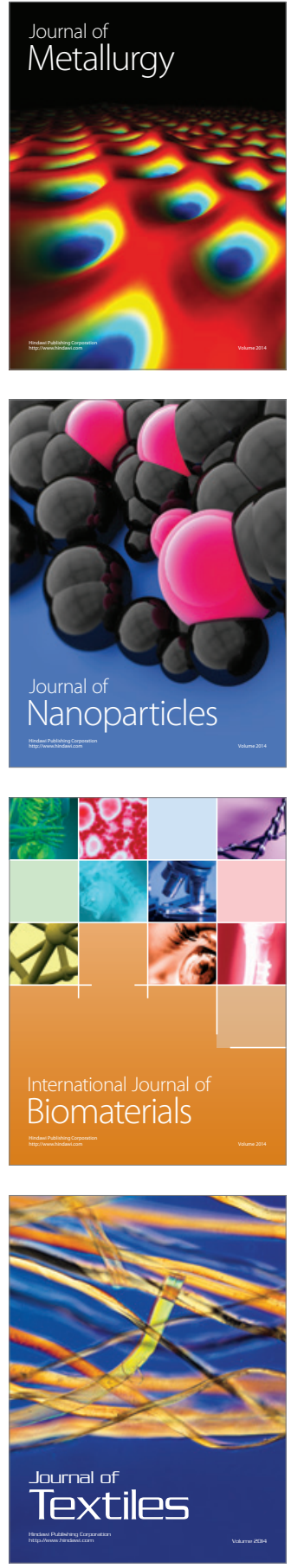